\title{
Transformative Communication as a Cultural Tool for Guiding Inquiry Science
}

\author{
JOSEPH L. POLMAN \\ University of Missouri-St. Louis, School of Education, Technology \& Learning Center, \\ St. Louis, MO 63121, USA \\ ROY D. PEA \\ SRI International, 333 Ravenswood Ave., Menlo Park, CA 94025, USA
}

Received 27 February 1999; revised 17 February 2000; accepted 17 March 2000

\begin{abstract}
Inquiry-based science instruction offers great promise as a means of actively engaging students in authentic scientific problem solving, including consideration of research design issues. At the same time, inquiry introduces some difficulties. In particular, familiar "cultural tools" for classroom discourse, such as Initiation-Reply-Evaluation sequences, are no longer appropriate because they are premised on known answers and teacher-driven activity. To help support productive open-ended science inquiry, coaching strategies that allow for strong student voice and teacher influence are necessary. We describe the sociocultural theory motivating one such strategy, transformative communication, as well as a specific dialogue sequence that can be used as a cultural tool for accomplishing such interaction. We then illustrate the utility of the dialogue sequence in four key episodes within an inquiry-based high school Earth Science class. (C) 2001 John Wiley \& Sons, Inc. Sci Ed 85:223-238, 2001.
\end{abstract}

\section{INTRODUCTION}

\section{The Need for Cultural Tools to Guide Science Inquiry}

Recent standards (National Research Council, 1996) stress the importance of inquiry as one aspect of teaching and learning science, but inquiry-based learning is still not the norm in schools. Research has for some time pointed out that classrooms and schools are complex cultural systems (Doyle, 1979; Sarason, 1971), where teachers cannot create change alone. In order to achieve the inquiry goals of the Standards, teachers must coordinate action with many students, and all must draw on an understanding of the cultural practices in which they are taking part in order to act. This is no easy task.

Teaching practices have been remarkably resistant to change, in part because they are

Correspondence to: J. L. Polman; e-mail: polman@umsl.edu

Contract grant sponsors: the National Science Foundation and the Illinois State Board of Education; contract grant numbers: RED-9454729 and MDR88-55582 
both familiar and well adapted to many of the goals and constraints of educators. Cuban (1984) argues that school and classroom structures have hindered the spread of childcentered instruction, such as that encouraged by the progressive movement and recent reforms. Specifically, schools and teachers use the various "batch processing" structures that today constitute the standard "grammar of schooling" (Tyack \& Tobin, 1994) to cope with the demand of teaching and keeping groups of up to 30 children in order. Examples include school structures, such as Carnegie units of academic credits, and classroom level structures, such as whole group question-and-answer sessions with students arranged at desks in rows.

The dominant discourse structure of teaching typified by question and answer sessions, or "recitation," has been closely examined by numerous researchers. In his observational studies of standard classroom "lessons," Mehan $(1978,1979)$ described how lessons are organized as sequences of events at various levels. At the most basic level, Mehan identified the dominant structure of discourse to be what he termed "Initiation-Reply-Evaluation" (IRE). In such a sequence, the teacher initiates an episode by asking a question about an established fact or idea they want to convey; students reply with bids for correct responses; the teacher evaluates the responses, and may initiate another round.

Lemke (1990) conducted related research in science classrooms and identified the same dominant discourse structure, which he labeled "Triadic Dialogue," or "QuestionAnswer-Evaluation." In such a sequence, the teacher opens with a question having a known answer, a student answers, and the teacher evaluates the adequacy of the answer. Extending to a longer time scale. multiple IRE sequences are often put together to form a "classroom lesson"- opening sequences to begin the class period, followed by topically related sets of sequences to cover instructional material, and closing sequences that end the class period.

One reason the recitation pattern of discourse is popular is that it is well adapted for traditional curriculum. Specifically, it suits situations in which the teacher is trying to simultaneously maintain a high degree of control in the classroom and also probe students' current understandings in order to help them to grasp a set of clearly specified concepts. But, it also has a cultural dimension that goes beyond its attractiveness from a purely utilitarian standpoint.

Consider the task of teachers and students in a class making use of this dominant discourse structure from a sociocultural standpoint (e.g., Leont'ev, 1981; Vygotsky, 1978; Wertsch, 1985, 1991). IRE can be seen as a "cultural tool" (Wertsch, 1991) that is familiar to most students after a couple of years in school and familiar to teachers from their own childhoods. Thus, both teachers and students understand well the "rules" of the "language game" (Wittgenstein, 1967) they are playing in interaction with one another: They know what sorts of roles that they are expected to play, what sorts of nuances indicate departure from the norm. and generally how one succeeds at participation.

Contrast the situation of participants in a classroom utilizing the IRE cultural tool to that of settings where students conduct open-ended project inquiry, such as that advocated by Dewey (1902). Since Dewey and the progressive movement, there has been periodic interest in having students learn science by doing science (e.g., reforms of the $1960 \mathrm{~s}$ beginning with Bruner, 1963). Recently, project-based pedagogy has been revived as a learning-by-doing teaching strategy that can promote students' active engagement with science (e.g., Krajcik, Czerniak, \& Berger, 1998; Pea, 1993; Ruopp, Gal, Drayton, \& Pfister, 1993). Interaction in project-based classes is difficult to base on the cultural tool of IRE, however, because IRE does not have appropriate "affordances" (Norman, 1988; Wertsch, 1998). ${ }^{.}$Specifically, IRE assumes that the teacher initiates interaction sequences

\footnotetext{
'As psychologists have used the term, "affordances" are the properties of a cultural tool that determine how it could be used, since the tool can be said to afford certain actions.
} 
with a question for which they have a known answer in the form of a target concept; in open-ended projects, however, actions are privileged over abstract concepts, and there is not usually one correct path for action. Since the project approach is still relatively uncommon, teachers and their students do not have an obvious set of well-established cultural tools to structure their interaction. Thus, how students should perform to achieve a good grade is highly ambiguous, and their perceived risk of failure correspondingly high. This fact can undermine the teachers' priority of maintaining order and fostering success among students. Dewey himself warned that "the mechanics of school organization and administration" (Dewey, 1901, p. 337) often doomed reforms, but his warning did not prevent such factors from affecting his own efforts.

Teachers who take seriously some version of the constructivist truism that knowledge must be actively constructed by learners, face a dilemma in inquiry classrooms, because they lack cultural tools for working together with students. Echoing Dewey $(1938,1950)$, Rogoff (1994) has warned against the pitfall of unguided discovery, where students are expected to be active discoverers of knowledge. but teachers remain passive and abdicate their responsibility as experts. As an alternative, Rogoff recommends a "community of learners" model based on the premise that "learning occurs as people participate in shared endeavors with others, with all playing active but asymmetrical roles" (p. 209). Teachers must learn to play a unique role of structuring and guiding student activities in the classroom without taking away the students' active role. Some researchers refer to this "middle ground" as "guided learning" or "guided participation." The role of guide, however, is difficult to master. As Brown (1992) says, "guided learning is easier to talk about than do. It takes clinical judgment to know when to intervene. Successful teachers must engage continually in on-line diagnosis of student understanding. They must be sensitive to overlapping zones of proximal development, where students are ripe for new learning" (p. 169). On top of the complexity of guiding students in project work, different students in a class need and receive different levels and kinds of support. Matching the kind and level of support students need with what a teacher gives them is a difficult balance to maintain. Consequently, as the teacher reported on in this study put it, he can "feel sort of like a tree swaying between two extremes of providing students with structure and allowing them to do it all themselves."

One way researchers have conceptualized teachers' new role in inquiry classrooms is as a coach of students in their work along the way (Collins, Brown, \& Newman, 1989). Although a good deal of research has been conducted on how mothers coach young children to perform simple tasks through social interaction (e.g., Rogoff, 1990; Wertsch, 1985), research has seldom focused on cultural tools for classroom teachers' effective coaching of complex tasks. Such research is most common for literacy (e.g., Cole, 1996; Palincsar \& Brown, 1984). In this article, we will describe a coaching strategy that has proved useful in inquiry-based science classes. The strategy is a particular discourse sequence enabling "transformative communication."

\section{APPLYING A VYGOTSKIAN VIEW OF COMMUNICATIVE ACTION TO SCIENCE INQUIRY}

Rogoff's (1990) concept of "guided participation" points to the importance of social arrangements to support human learning. Examples of such arrangements include Palincsar and Brown's (1984) influential model of "reciprocal teaching," in which the teacher places students in roles that divide up important aspects of the reading task, supports the accomplishment of those roles, and through repeated activity involving role shifts for students, brings the group as a whole to more expert performance.

Reciprocal teaching strategies are based on Vygotsky's (1978) "general genetic law of 
cultural development." Vygotsky held that learners' accomplishment of activities with the help of more expert others, through social interaction, provide the seeds for individual learning. The "intermental" action (Wertsch, 1991) that occurs between minds allows for "performance before competence" (Cazden, 1981), because the learner could not perform at a comparable level if working alone. After such performance on the intermental plane, learners can advance their own understanding, by appropriating the experience to the "intramental" plane (i.e., in an individual's mind). In Vygotsky's terminology, the "zone of proximal development" (ZPD) describes the limit of actions that learners can meaningfully participate in intermentally. While in the ZPD, learners and teachers maintain "intersubjectivity" (Rommetveit, 1979) so that their intramental understandings coincide enough to coordinate intermental action, and learners subsequently have the opportunity to appropriate new intramental understandings. Beyond the ZPD, learners cannot relate actions to their current intramental understandings.

How science teachers and students can accomplish activity in the ZPD is not at all straightforward. How do teachers know where students are developmentally? And what do students' contributions look like when they are performing "meaningfully" but not yet "competent?" How do you avoid going outside the zone and losing intersubjectivity?

We faced such questions in our work within the Learning through Collaborative Visualization (CoVis) project (Pea, 1993). CoVis was a multi-year effort, funded by the National Science Foundation, aimed at incorporating emerging computing and Internet technologies into science education reform toward project-based (or inquiry) instruction. In most of our classrooms, students faced a "bootstrapping" dilemma: They had few experiences that helped them to know how to carry out certain aspects of science inquiry. Thus, if the teacher just gave them a clearly circumscribed path, as is done in many "cookbook" labs, the meaning of students' actions would not necessarily relate to the teacher's goal of students learning about experimental design (because the students were not required to meaningfully participate in the design).

This problem is also too often manifest in various forms of student-scientist partnerships in education (Cohen, 1997). In studies such as the multinational precollege GLOBE Project (Global Learning through Observations to Benefit the Environment), students collect data around the world. They do so according to protocols that are designed by scientists to ensure data quality and reliability. Even though student involvement is often messy from scientists' perspectives, it is educationally significant (Pea et al., 1997); without care in such a situation, learners may be relegated to the role of "databots," collecting data without an understanding of the designs which render it meaningful. To involve students, teachers need to "negotiate with [students] without taking over," as the teacher reported on in the research put it. When trying to help students formulate their own viable research questions that can be addressed by data acquisition and analysis, this teacher said, "I don't want to give them the question. I want them to generate a question. But how do I help them to do that? There's no clear path." What is needed is some kind of interactive process of guided participation, which allows the student to be an active inquirer and the teacher to be an active guide. "Transformative communication" is one such process for guiding participation (Pea, 1994), and we have come to see that it provides some explanation of why certain incidents proved productive for teaching and learning in a project-based science classroom.

The view of communication as transformative can be contrasted with common views of communication as ritual and as transmission (Pea, 1994). The view of communication as ritual tends to encourage active participation by all parties, but in activities with already shared meanings. The ritual nature of much cultural activity helps to explain how it is successfully carried out; for instance, telephone greetings rely on a highly specific series 
of key words, pauses, and intonations to get a great deal of information across quickly (Schegloff, 1979). Despite the obvious importance of ritual communication in cultural activity, it does not involve the sort of generativity at fostering new development that is needed for education. The dominant view of communication in learning settings as transmission of knowledge from the teacher to the student (Cohen, 1988; Pea, 1994), as in a lecture, tends to leave students passive. An alternative to the ritual and transmission views is transformative communication, which Pea (1994) has described as:

... the initiate in new ways of thinking and knowing in education and learning practices is transformed by the process of communication with the cultural messages of others, but so, too, is the other (whether teacher or peer) in what is learned about the unique voice and understanding of the initiate. Each participant potentially provides creative resources for transforming existing practice. (p. 288)

Transformative communication is thus achieved through mutual appropriation (Newman, Griffin. \& Cole. 1984) by participants in social interaction to create meanings that neither participant alone brings to the interaction.

In order to better specify how transformative communication could uniquely work in inquiry science classrooms, we turned to classroom observations (see the section entitled "Methods and Data Sources for Example Episodes" for more detail). In project-based science classrooms designed to support students in carrying out their own original research, the main work involves transforming students' actions into more successful "moves" in the "language game" of science (Wittgenstein, 1967). After identifying episodes from classroom observation that both matched the theory previously described and played a pivotal role in the success of research projects, we recognized a common pattern in the dialogue between teacher and students. The dialogue sequence we identified for achieving transformative communication is as follows:

1. Students make a move in the research process with certain intentions, guided. as well as limited by, their current knowledge.

2. The teacher does not expect the students' move, given a sense of their competencies, but understands how the move, if pursued, can have additional implications in the research process that the students may not have intended.

3. The teacher reinterprets the student move, and together students and teacher reach mutual insights about the students' research project through questions, suggestions. and/or reference to artifacts.

4. The meaning of the original action is transformed, and learning takes place in the students' zone of proximal development, as the teachers' interpretation and reappraisal (i.e., appropriation) of the students' move is taken up by the student.

The reason this dialogue sequence is transformative is that it allows initial student actions and ideas to be incorporated into later teacher-influenced actions which push students' development and learning, while maintaining intersubjectivity between teacher and students. It takes advantage of the fact that science teachers who know a good deal about research design and analysis can conduct what Schön (1982) refers to as "frame experiments" about possible future research directions. Like architects who are "likely to find new and unexpected meanings in the changes they produce [in their drawings] and to redirect their moves in response to such discoveries" (p. 103), teachers may see "new and unexpected meanings" that their students produce by introducing ideas or facts into a science research project. Tracing the participants' "situation definitions" (Wertsch, 1985) 
through the four steps reveals the important affordances of this sequence as a cultural tool. Students' understanding of scientific research design issues are more limited than their teacher's, so their verbal or written move in step one is made from a limited initial situation definition. But in step two, the teacher can project other potential situation definitions using the same raw materials that the student had introduced. By making step three "bound" (Rommetveit, 1979) to students" utterances from step one, the teacher can create a new "shared situation definition" that matches a more sophisticated definition than the students had originally introduced. If the students are able to appropriate it in step four, successful transformative communication has occurred.

\section{METHODS AND DATA SOURCES FOR EXAMPLE EPISODES}

Of course, theoretical notions, such as transformative communication, and hypothetical dialogue sequences, such as that described previously, are only useful for educational practitioners insofar as they can be related to specific learning environments and conversations. For the balance of this article, we will detail episodes involving transformative communication from research in one high school Earth Science classroom. A central goal of the class was that students should participate in the formulation of research questions. the gathering of data to provide empirical evidence for addressing their questions, analysis of those data, and reporting in both written and oral format.

The episodes related in this article are taken from an interpretive case study (Polman, 1997, 2000) conducted in Rory Wagner' ${ }^{2}$ class, one of many participating in the largescale CoVis reform project. The term interpretive refers to any form of participant observational research that is centrally concerned with the role of meaning in social life, enacted in local situations (Erickson, 1986). The first author was a participant observer in Wagner's classroom for 3 years: data reported here are from one project period from November 1995 to February 1996. During that period, Polman shadowed the teacher and observed all interactions between Wagner and his students on 28 of 48 class days, and conducted debriefing interviews by phone following 14 more classes (leaving 6 days for which no field notes were recorded). Ten of the 28 observation days. selected to be spread across the seven phases of projects identified in earlier observations, were videotaped and transcribed; handwritten notes were taken on all days during class and filled in later when typed out. Artifacts created by the teacher and students were copied. Participants' perspectives on projects in general and particular classroom events were clarified through four formal audiotaped interviews with the teacher on his history of project work, running a project-based classroom, and supporting specific projects, and formal audiotaped interviews with selected focus students before and after their projects, as well as informal interactions between Polman and participants during and after class. All these data were entered into electronic form and coded on numerous predetermined and emergent dimensions in a software package. For this study, use of these data is limited to explicating transformative communication in the accomplishment of projects.

Given the nature of our data and purpose, we do not conduct quantitative analyses of the transformative communication episodes identified in this corpus. Instead, we selected four episodes that proved to be crucial to the success of the projects of which they were a part. By "crucial" we mean that the episodes resulted in students appropriating strategies they provide no indication of understanding prior to the episodes, at junctures in the projects where students most often go awry: research question formulation and using data

${ }^{2}$ At his request, Rory Wagner's real name is used. All students' names are pseudonyms. 
analysis to support a conclusion. We examine the sequence and structural qualities of these episodes in detail. We do not intend to imply that all communication that results in learning is transformative in the manner described here. Nor do we mean to imply that all communication that could reasonably be termed transformative follows this sequence in strict stepwise order; the sequence is intended to describe the general trajectory of these crucial dialogues. The dialogues inevitably involve a great deal of interactive give-and-take which we are not going to examine at the level of detail afforded by, for instance, conversation analysis. What we hope to accomplish with this dialogue sequence is two-fold: to describe important features of dialogue which have proved productive in transformative teachinglearning episodes, and to provide a description of the discourse strategy at a level allowing science teachers to productively use it as a cultural tool for coaching their students in inquiry.

\section{Plesiosaurs: Transforming a Quest for Facts into a Research Question}

Three juniors who sat at the middle table of Rory Wagner's classroom teamed up for their first project. Beth and Laura were both gregarious and had participated frequently in class discussions during Wagner's lectures given during the first quarter of the year. Cindy, on the other hand, was usually quiet.

After toying with a number of topics for their project, like voleanic islands, Cindy and Laura began exploring dinosaurs, and then focused on the plesiosaur. Beth was absent the day they made the choice, but was quickly just as enamored of the creature as the others. They could be heard to repeat the creature's name slowly, relishing its sound. and they showed anyone willing pictures of the long-necked creature which lived in the sea.

During the first few weeks of projects, Wagner had the students collect "background information" on their chosen topics. Beth, Laura, and Cindy initially had a great deal of trouble locating specific details on the plesiosaur, but with Wagner's help began to learn how to use the Internet, which they could access from computers in their room, and they ended up tracking down some useful resources on the World Wide Web and Usenet newsgroups. Along with some library books, they used the information to write up a background information report, which was one of Wagner's "milestones" to completing the 10-week project. The complete series of milestones were: 1) select group and topic, 2) write up background information, 3) provide research question/proposal, 4) collect data, 5) analyze data, 6) complete research report modeled on the scientific research article genre, 7) revise research report, and 8) present findings to the class. This series of milestone assignments embodied the classroom "activity structure" (Lemke, 1990) for accomplishing projects at a quarter-long time scale. In other work, Polman $(1997,2000)$ explores the nature of this broader activity structure in more detail. The most important feature of the written milestone artifacts for our purposes here is that they were "sharable and critiquable externalizations of students' cognitive work" (Blumenfeld et al., 1991, p. 370) that become useful as occasions for feedback and transformative communication.

During the following week, the plesiosaur group had to propose their focused research question. Beth and Cindy proposed the research question, "Are accumulations of plesiosaurs associated with areas of high marine productivity?" Wagner indicated several problems with the question to the students. Although it suggested a workable empirical analysis - comparing the fossil records on the number of plesiosaur skeletons to indicators of marine productivity - the results would be of dubious use, since high animal population does not directly correspond to fossil formation or discovery. To avoid these pitfalls, Wagner asked them to step back, saying, "What drew you to plesiosaurs in the first place?" Cindy talked about their long necks, and Beth about how they swam. Since Wagner re- 
called Beth's mention two weeks earlier of a question in some of her books about how quickly plesiosaurs swam, he encouraged them to pursue an "analysis of plesiosaur swimming motion." The group liked the idea, since, as Beth said, it was like "the reanalysis of dinosaurs that they did, and whether they were slow or fast - Jurassic Park was more accurate than the old picture of lumbering dinosaurs."

After deciding to focus on plesiosaur swimming motion, the group members went to review the relevant sections in the library books they had gathered, and Beth returned a few days later saying incredulously, "Mr. Wagner! Do you know whether the plesiosaur moved by rowing its flippers or flapping them like wings?" One of her library books stated that plesiosaurs swam with a rowing motion, and another book stated that they swam by "underwater flight," flapping their flippers like wings straight up and down in the water. Neither book mentioned a controversy. As Beth told me later, "I thought he was like allknowing, that he like knew there was this controversy, but he didn't" (all quotations that are not part of classroom action are from interviews). Beth was also looking for Wagner to provide the answer, the kind needed for what Wagner called a "traditional library research" project. She told me she "had never done a project where there hasn't been really an answer, or someone who's already found the answer." But instead, Wagner responded, "I don't know. Why don t you have that be your research question?" Wagner showed Beth that her question about the swimming method could be the question in their research project - they could assemble evidence and figure out which swimming motion they thought it was.

Through this interaction, Wagner was able to support Beth in accomplishing an activity with which she was unfamiliar, by means of the sort of "transformative communication" described earlier. We can see a concrete enactment of the four-stage dialogue sequence:

1. Beth approached Wagner with the following situation definition: she was looking for the answer to a fact-based question that she expected her "all-knowing" teacher to provide (did plesiosaurs swim by underwater flight or rowing motion?) If she could get the answer, she would include it in their report on plesiosaurs, which she may have viewed as a synthesis of established facts about a topic, much like she d done in other classes.

2. Wagner did not know the fact Beth was looking for, nor did he even know there was a debate about plesiosaur swimming motion, but he saw the possibility for incorporating Beth's question into a different situation definition. He knew that part of the game of science involves marshaling evidence to support one of several competing claims, such as the ones in the books Beth had found.

3. Wagner reinterpreted Beth's move, creating a new shared situation definition for the discrepant claims: an opportunity to contribute new evidence to a scientific debate rather than just report others' findings.

4. Beth's fact question was transformed into a research question, as evidenced in her subsequent practice.

\section{UFO Sightings: Transforming a Citation into Confirming/Disconfirming Research}

Researchers on project-based learning have pointed out that motivational benefits can be reaped when students are given control over decisions about what they do - as Wagner gave Beth and her project partners-and when they are given the opportunity to work on problems and projects that interest them (Blumenfeld et al., 1991). The problem with starting from students' interests, as Wagner noted, is that it is "awful hard" in many cases 
"to transform something you are really interested in to something you can do" as scientific research. Bruce, Sylvia, and Cheryl's project shows how a project built on students' interests which were seemingly dubious from a scientific standpoint could be transformed into empirical research that was "doable." Through transformative communication, their project went from being a project about "whether UFOs are alien space ships" to a project about confirming or falsifying natural explanations of UFO sightings.

Along with the other groups, the UFO sightings group began the project by collecting and synthesizing background research on the topic before deciding on a specific research question. In their interim report of background research, they mentioned the so-called "Condon report" (Condon \& Gillmor, 1968), the only official study of UFO sightings published by the U.S. government. Condon and colleagues claimed UFO sightings could be explained by meteor showers, rocket launches, and other known phenomena. Wagner was intrigued by the fact that Condon's analysis took an empirical approach based on supportable or refutable claims about alternate explanations for UFO sightings - a scientific approach to a problem usually approached through mere hearsay. So during class one day, Wagner initiated a discussion with the UFO sightings group about potential research questions. The interaction with the UFO sightings group proved pivotal in formulating a specific research question and served as another example of transformative communication.

Wagner approached Cheryl, Bruce, and Sylvia, saying, "O.K., you guys," as he sat down with them. The following interaction took place:

Wagner: O.K., what do you want to do?

Bruce: We want to show UFOs are alien space ships.

Wagner: [doubtfully] Any ideas on how?

Bruce: I don't think there's any way to prove it unless they saw the alien in there and they waved at them. That's the only evidence there is.

Wagner: Right. That's the problem . . . You know, . . . the analysis Condon did that you wrote about in your background information [report]. It was interesting because Condon claimed to have explained the sightings with known phenomena. [For your project] you could verify what somebody like Condon has done. That's another thing people do in science ...

He mentioned the example of the cold fusion debate a few years ago, and then pointed to how they could take a similar tack of trying to verify someone else's findings:

Say [the government report] said it was a meteor shower. You could look at the date, where the meteor shower was, and when and where people saw the UFO. Does it match the same spot? If the sighting was here / points one direction] and the meteor shower there [points another direction] the government's explanation could be wrong.

Wagner stressed that they need not follow his suggestion. Besides opportunity for learning through a greater level of student participation, Wagner's policy of not forcing students to follow his recommendations was part of a general policy of leaving a large amount of responsibility with the students. If he forced students to follow his recommendations, students were likely to claim he alone was responsible if their efforts did not turn out well, as a way of weaseling out of making improvements. But if students worked together with him in earlier stages and had a strong voice in decision making, they could establish coownership. With co-ownership of the project, students were more likely to be willing to 
work together with Wagner to figure out productive alternatives if they encountered difficulties and dialogue with the students remained more productive.

The students decided to pursue the idea. In this example, the students originally presented the Condon Report as relevant to the history of the UFO debate, and thus something to be cited. Through their interaction, Wagner and the students created a new meaning for the citation: the seeds of a study intended to provide independent confirmation or falsification. Thus, this sequence of interactions, starting with the submission of the report by the students and continuing with the discussion in class, can be seen as another instance of transformative communication. The students referred to some research in their interim report, intending it as an example of what was known and had been reported about their subject. Wagner showed them they could treat the study as the seeds for the next phase of the activity: a research proposal to independently confirm or falsify the previous research. With this formulation in place, the students carried out a successful project.

\section{TRANSFORMATIONS IN THE DATA ANALYSIS PHASE OF INQUIRY}

Rory Wagner felt that the "beginning of the project and the end of the project" were the most difficult for students conducting open-ended inquiry. Specifically, at the early phase, students needed to formulate a research question and proposal, and, at the later phase, they needed to use data analysis to reach an empirically supported conclusion. The cases described thus far provide examples of transformative communication during research question formulation. The Hurricanes and the Moons cases provide examples of transformative communication at the data analysis phase.

\section{Hurricanes Project}

Dave and TJ became interested in hurricanes because of the destruction they cause. Through conversations with Wagner and a scientist with whom Wagner put them in email correspondence, they settled on the research question, "Is there a preferred pattern of hurricane movement in the Northern Hemisphere?"

$\mathrm{TJ}$ and Dave worked diligently to gather images showing hurricane paths for a series of years off a web site. To compare the paths from more than one year's image, TJ came up with the idea of tracing hurricane paths by hand off the computer screen onto transparencies, which could be laid on top of one another. Wagner challenged them to figure out "what the data [said]," and Dave stated in an early interview that "most [hurricanes] make a little semicircle," which he drew as a C-like shape swooping from southeast to northwest to northeast. But turning his impression into an empirically supported argument proved difficult for Dave and his partner. With a day to go before their research report was due, Dave and TJ had a long conversation with Wagner trying to solidify data analysis techniques. Wagner asked them what the general pattern of hurricanes was, and TJ showed him the $C$ shape. Wagner made a few suggestions for ways to systematically describe hurricane shapes, while they continued to look over the large set of paths on transparencies. Then Wagner noticed that not all the hurricanes had the C-shaped paths Dave and TJ had described. Some were straighter, and others appeared erratic. He then suggested they could devise a categorization scheme for the shapes of paths. They could go back to each year. count up the frequencies of each shape, and calculate the percentages.

Not surprisingly, Dave and TJ's incorporation of these ideas was only cursory in the report they turned in the next day. In his extensive commentaries written on the paper, Wagner noted they "made statements in [the] analysis section without referring to the data once. You can't do that." For instance, TJ and Dave had written, "We found that most of 
the recorded storms began in the Atlantic Ocean, east of the Caribbean, and made a C-like shape towards the United States and finished back east of the northern United States." Wagner suggested, among other things, that they specifically show "exactly how many (and then, what percentage) of the storms had this 'C-shape' path." For their revised report, the pair categorized each storm as having one of three path shapes and gave the number of storms within each category among the 83 storms over the period. They also produced a pie chart showing that $50 \%$ were C-shaped, $22 \%$ "Straight-C", and $27 \%$ ir regular. The hurricane group's revised report was a significant improvement over their first draft, with conclusions supported specifically by data analysis.

In this example, Wagner had to repeat step three of the dialogue sequence, in which he reinterpreted students' original "move," because they initially failed to share his situation definition about empirical supports for research claims. In the classroom discussion and again in their paper, the students made a claim about the dominant path shape without knowing how to support it with specific reference to their data. The first time, Wagner verbally suggested a coding scheme and counting, but the idea was not taken up (appropriated) by the students. But, when he suggested again, and with more specific written directives on their paper, the students were able to appropriate the strategy.

\section{Moons Project}

Rich and Steve did a project comparing and contrasting moons in our solar system. They had gathered data on various characteristics of moons, such as density, size. mass, and orbital period, and meticulously organized it in tables and graphs - a separate graph for each variable. In numerous conversations and comments on interim milestones, Wagner had pushed them to think about questions their data could illuminate, such as "Why are they different from one another?" But the students were unable to see patterns in the data, until, as Steve said, Wagner "kind of helped us out a little bit."

The crucial exchange began when Wagner received Rich and Steve's final research report. The students had included only graphs of single variables and then listed each graph's interpretation separately. For instance, they included the graphs of each moon's orbital time period and density, as shown in Figure 1.

In the text, they wrote statements such as, "the graph [of orbital period] shows that Earth's moon has the longest orbital period, 27.32 days, while Miranda has the shortest orbital period, 1.4 days." Similar graphs in different styles were included for mass, surface temperature, and distance from planet. In the Data Analysis section of the paper, Steve and Rich did not mention relationships between variables. But, at the end of the paper,

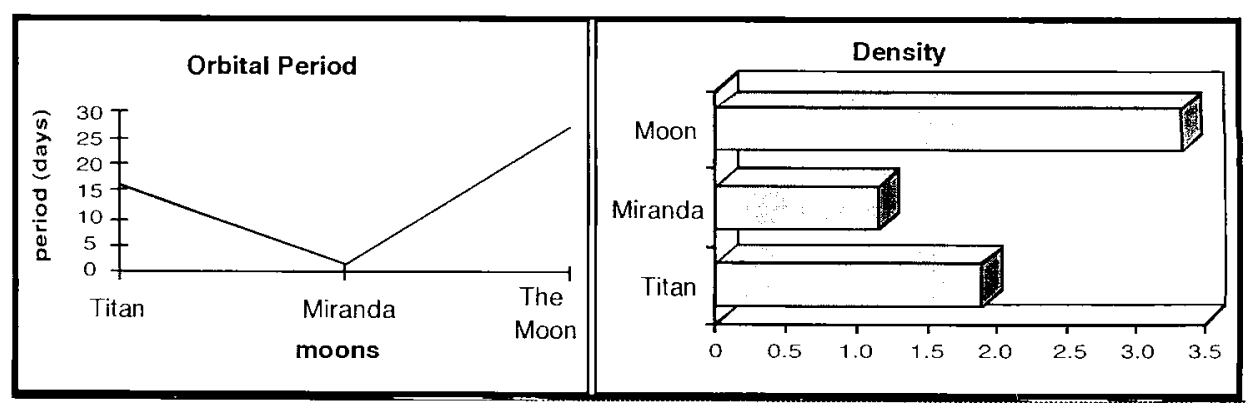

Figure 1. Orbital period and density of three moons from final draft. 
buried in the Conclusion, something more like a testable claim appeared. They had written, "We have come [to] the conclusion that both Titan and Earth's moon [have] a much greater mass and density than Miranda, and that this could be why both Titan and Earth's moon have longer orbiting time periods." Wagner latched onto this claim about how mass and density could be related to the orbital period of the moons and showed Rich and Steve how they could directly test it using their data, with graphs combining variables. He sketched a number of graphs like Figure 2.

Once again, Wagner saw how something that the students had done could be transformed to a more successful "move" in the "game" of science than they themselves were originally aware. In the course of working with the data and looking at the graphs over a period of time, Rich and Steve developed a sense that this relationship exists; that is why they put the comment in their conclusion. As we saw in the Hurricanes case, however. a clear analysis technique may be difficult for inexperienced students to find even after a general impression had been reached by working with the data. In this case, Steve and Rich did not know how to construct a graph to directly test their claim. In fact, the graphs they had in their data analysis were not conducive to checking the relationships the students themselves mentioned in their conclusion-as shown in Figure 1, one graph was a horizontal bar while the other a vertical line. Wagner sketched graphs of one variable against the other to directly check the claim: It appeared that in the students' data, a relationship between density and orbital period was supported, but not between mass and time period. Using similar methods, Wagner suggested that the students could create combination graphs for all possible pairs of variables. In this way, another apparent linear relationship was revealed, between the mass of a moon and its distance from the planet.

When Steve and Rich got the final version of the paper back, they were excited. As Steve put it, "We finally saw what we were trying to find, with the patterns, by looking at those graphs . . . and that was . . . a good thing, seeing relationships." Although there was no provision for revising their paper again, the students got a chance to use this insight in their presentation to the class the following week. Steve and Rich created graphs of their own using Wagner's sketches as a model. In their presentation, they used the line graphs of two variables to support their claims, such as the one that "if a moon has a greater mass, that might affect its distance from [its] planet." With statements about one factor "contributing to" or being "affected by" another, Rich and Steve had finally moved into the realm of making empirically warranted causal arguments, albeit tentative and somewhat awkwardly stated ones. As in the scientific community, they made their claims



Figure 2. Rory Wagner's sketched graph ("Luna" is Earth's moon). 
with the aid of particular inscriptions - in this case, somewhat crude graphs. The graphs made their claim more compelling and understandable (Latour, 1988). In addition, they were able to see possible extensions of the work they'd done: unprompted, Rich mentioned a follow up project could "compare even more data, put them together, [and] see if there's a pattern."

Steve and Rich had a great deal to learn about analyzing data, but transformative communication helped them begin making progress.

\section{DISCUSSION AND CONCLUSIONS}

Rory Wagner wanted to ensure that students participated in research design and the selection of analysis techniques so that they could learn about research design and analysis strategies. This contrasts to traditional "cookbook" labs, which take such decisions out of the hands of students, and thereby preclude opportunities for deeper learning likely to lead to autonomous action in the future. But, as already mentioned, involving students can be time-consuming and difficult. Transformative communication helps to maintain the necessary balance between student ownership and teacher "control," since both parties make crucial contributions.

\section{Mutual Insights through Conversation with One Another and the Situation}

In the episodes described, Wagner helped the students transform the moves they made in the research process with limited understanding into more sophisticated moves that neither he nor the students would have originally predicted, thus leading to mutual insights. The interactions sometimes took place over an extended period of time, in both verbal and written communication; the important thing is that both teacher and student participation contributed. To borrow a phrase from Schön (1982), the process of transformative communication enabled both Wagner and his students to "engage in a conversation with the situation which they [were] shaping" (p. 103); but in this case, it also allowed them to engage in a conversation with each other. Wagner and his students found new and unexpected meanings in the changes they produced in one another's interpretations and the situation. As Wagner tried to tell the students, they did know important and useful things about their topic and data as they researched their topic, but he often needed to help them see how what they knew could be used to accomplish scientific inquiry. Wagner and the students came "to appreciate and then to develop the implications of a whole new idea" (Schön, p. 95).

\section{Breakdowns in Transformative Communication}

The development of these new ideas and unanticipated possibilities was facilitated by the four-step dialogue sequence of transformative communication, but does not guarantee success. In other words, each step enables the next, but does not cause it. We intentionally chose to examine successful episodes to better understand their features and workings, but breakdowns do occur. From a functional standpoint, several points can be made about breakdowns. To get from step one to step two, the teacher must both perceive students' actions (and there are many actions in a project-based class outside the purview of the teacher) and must have the knowledge to imagine alternative "paths" the students' research could take. The greater the teacher's science knowledge, the more possibilities they could imagine. Both motivational and cognitive breakdowns could prevent students and teachers from successfully getting to step three (teacher and students reinterpreting and negotiating 
the meaning of an alternative move) and step four (students taking up the new move). Rory Wagner and his students, for instance, sometimes discussed a research question, but the students chose another idea on the table over Wagner's recommendation because they found it more interesting. In the case of Dave and TJ, explicated previously, Wagner's first attempt at step three was not understood by the students. Examining in detail when and how breakdowns occur in getting from one step to the next is beyond the scope of this article, but such research would be valuable.

\section{Learning in the ZPD}

Although the focus of our research is not on individual appropriation or learning per se, we would like to point out some evidence in Beth's case of how these mutual insights in action can result in individual learning. Again, the Vygotskian notion of the ZPD suggests that the activity which Beth and Wagner accomplished on the intermental or social plane could result in learning on the intramental or individual cognitive plane. Wagner helped Beth see that claims about the phenomenon of plesiosaur swimming motion need not be accepted as simple "fact" or "fiction," and together they figured out strategies for independently confirming or falsifying the claims by assembling independent data. In her next project, Beth chose underground nuclear testing as her topic and encountered claims from environmental organizations that such testing caused geologic damage. She was still working with milestones that supported her in important ways, such as prompting for research questions and data to address the questions. But there was one aspect of action that had been performed by Wagner in the first project, in dialogue with Beth, that she performed without the benefit of social support later. After further research on underground nuclear testing, she suggested, with no prompting from Wagner, that the environmental organizations were making catastrophic claims without supporting data. She had, in an important sense, learned the need for and nature of adequate evidence to support scientific claims.

\section{Looking Back and Ahead}

Project-based science teaching and learning involve complex role changes for teachers and students. Too often, the complex work teachers perform as facilitators and guides for project-based student work is left mysterious. In this article, we presented the theory behind transformative communication and a dialogue sequence teachers can use to achieve such communication when acting as facilitators. We also elaborated concrete cases in which the strategy had been used successfully to help students accomplish projects more sophisticated than they could originally conceive. Our intention is to provide readers with a powerful cultural tool for use in other inquiry science settings. Further research will surely refine and expand our understanding of how to effectively guide learners in inquiry tasks without prespecified answers.

The writing was completed with the support of a fellowship from the James S. McDonnell Foundation to the first author. The statements made and the views expressed are solely the responsibility of the authors.

\section{REFERENCES}

Blumenfeld, P. C., Soloway, E., Marx, R. W., Krajcik, J. S., Guzdial, M., \& Palincsar, A. (1991). Motivating project-based learning: Sustaining the doing, supporting the learning. Educational Psychologist, 26(3), 369-398. 
Brown, A. L. (1992). Design experiments: Theoretical and methodological challenges in creating complex interventions in classroom settings. Journal of the Learning Sciences, 2(2), 141-178.

Bruner, J. (1963). The process of education. New York: Vintage.

Cazden, C. (1981). Performance before competence: Assistance to child discourse in the zone of proximal development. Quarterly Newsletter of the Laboratory of Comparative Human Cognition, $3,5-8$.

Cohen, D. K. (1988). Teaching practice: Plus ça change . . . In P. Jackson (Ed.), Contributing to educational change: Perspectives on research and practice. Berkeley, CA: McCutchan.

Cohen, K. (Ed.). (1997). Internet links for science education: Student-scientist partnerships. New York: Plenum Press.

Cole, M. (1996). Cultural psychology: A once and future discipline. Cambridge, MA: Belknap Press of Harvard University Press.

Collins, A., Brown, J. S., \& Newman, S. E. (1989). Cognitive apprenticeship: Teaching the craft of reading, writing, and mathematics. In L. B. Resnick (Ed.), Knowing, learning, and instruction: Essays in honor of Robert Glaser (pp. 453-494). Hillsdale, NJ: Erlbaum.

Condon, E. U., \& Gillmor, D. S. (1968). Final report of the scientific study of unidentified flying objects. New York: Bantam Books.

Cuban, L. (1984). How teachers taught. New York: Longman.

Dewey, J. (1901). The situation as regards the course of study. Journal of the Proceedings and Addresses of the Fortieth Annual Meeting of the National Education Association, 332-348.

Dewey, J. (1902). The child and the curriculum. In J. J. McDermott (Ed.), The philosophy of John Dewey, Vol. II: The lived experience (pp. 467-483). New York: G. P. Putnam's Sons.

Dewey, J. (1938, 1950). Experience and education. New York: Macmillan.

Doyle, W. (1979). Classroom tasks and students' abilities. In P. L. Peterson \& H. L. Walberg (Eds.), Research on teaching: Concepts, findings, and implications. Berkeley, CA: McCutcheon.

Erickson, F. (1986). Qualitative methods in research on teaching. In M. C. Wittrock (Ed.), Handbook of research on teaching. New York: Macmillan.

Krajcik, J., Czerniak, C. M., \& Berger, C. F. (1998). Teaching children science: A project-based approach. Boston: McGraw-Hill.

Latour, B. (1988). Drawing things together. In M. Lynch \& S. Woolgar (Eds.), Representation in scientific practice. Cambridge, MA: MIT Press.

Lemke, J. L. (1990). Talking science: Language, learning, and values. Norwood, NJ: Ablex.

Leont'ev, A. N. (1981). The problem of activity in psychology. In J. V. Wertsch (Ed.), The concept of activity in Soviet psychology (pp. 37-71). Armonk, NY: M. E. Sharpe.

Mehan, H. (1978). Structuring school structure. Harvard Educational Review, 48(1), 32-64.

National Research Council (1996). National science education standards. Washington, DC: National Academy Press.

Newman, D., Griffin, P., \& Cole, M. (1984). Social constraints in laboratory and classroom tasks. In B. Rogoff \& J. Lave (Eds.), Everyday cognition: Its development in social context. Cambridge, MA: Harvard University Press.

Norman, D. (1988). The psychology of everyday things. New York: Basic Books.

Palincsar, A. S., \& Brown, A. L. (1984). Reciprocal teaching of comprehension-fostering and comprehension monitoring activities. Cognition and Instruction, 1, 117-175.

Pea, R. D. (1992). Augmenting the discourse of learning with computer-based learning environments. In E. de Corte, M. Linn, H. Mandl, \& L. Verschaffel (Eds.), Computer-based leaming environments and problem-solving (pp. 313-344). New York: Springer Verlag.

Pea, R. D. (1993). The collaborative visualization project. Communications of the ACM, 36(5), $60-$ 63.

Pea, R. D. (1994). Seeing what we build together: Distributed multimedia leaming environments for transformative communications. The Journal of the Lcarning Sciences, 3(3), 285-299.

Pea, R. D., Gomez, L. M., Edelson, D. C., Fishman, B. J., Gordin, D. N., \& O'Neill, D. K. (1997). Science education as a driver of cyberspace technology development. In K. C. Cohen (Ed.), Internet links for science education: Student-scientist partnerships (pp. 189-220). New York: Plenum Press. 
Polman, J. L. (1997). Guiding science expeditions: The design of a learning environment for projectbased science. (Doctoral dissertation, Northwestern University, 1997). Dissertation Abstracts International, Accession No. ADG9731316.

Polman, J. L. (2000). Designing project-based science: Connecting learners through guided inquiry. New York: Teachers College Press.

Rogoff, B. (1990). Apprenticeship in thinking: Cognitive development in social context. New York: Oxford University Press.

Rogoff, B. (1994). Developing understanding of the idea of communities of learners. Mind, Culture, and Activity, 1(4), 209-229.

Rommetveit, R. (1979). On the architecture of intersubjectivity. In R. Rommetveit \& R. M. Blakar, Studies of thought and verbal communication. London: Academic Press.

Ruopp, R., Gal, S., Drayton, B., \& Pfister, M. (Eds.). (1993). LabNet: Toward a community of practice. Hillsdale, NJ: Lawrence Erlbaum Associates.

Sarason, S. B. (1971). The culture of the school and the problem of change. Boston: Allyn and Bacon.

Schegloff, E. A. (1979). Identification and recognition in telephone conversation openings. In G. Psathas (Ed.), Everyday language: Studies in ethnomethodology (pp. 23-78). New York: Irvington Publishers.

Schön, D. A. (1982). The reflective practitioner: How professionals think in action. New York: Basic Books.

Tyack, D., \& Tobin, W. (1994). The "grammar" of schooling: Why has it been so hard to change? American Educational Research Journal, 31(3), 453-479.

Vygotsky, L. S. (1978). Mind in Society. Cambridge, MA: Harvard University Press.

Wagner, R. (1996). Personal communication.

Wertsch, J. V. (1985). Vygotsky and the social formation of mind. Cambridge, MA: Harvard University Press.

Wertsch, J. V. (1991). Voices of the mind: A sociocultural approach to mediated action. Cambridge, MA: Harvard University Press.

Wertsch, J. V. (1998). Mind as action. New York: Oxford University Press.

Wittgenstein, L. (1967). Philosophical investigations. Oxford: Blackwell. 